\title{
EDUCATION ON VIRTUAL ORGANIZATIONS: AN EXPERIENCE AT UNL
}

\author{
L. M. Camarinha-Matos, T. Cardoso \\ New University of Lisbon, Faculty of Sciences and Technology \\ Quinta da Torre, 2829-516 Monte Caparica,PORTUGAL, cam@uninova.pt
}

\begin{abstract}
The introduction of new courses on virtual organizations at the engineering education level is an important element for the broad acceptance of this new paradigm. This article summarizes the experience with an initiative of teaching Virtual Enterprises / Virtual Organizations subjects to Electrical and Computer Engineering students. The course structure, both in its lecture and lab work components, is described. Finally, some lessons learned with two editions of this course are presented.
\end{abstract}

\section{INTRODUCTION}

Education can play a vital role in facilitating the dissemination and broad acceptance of the virtual organizations paradigm. The practical development and exploitation of new collaborative network forms such as virtual organizations / virtual enterprises, professional virtual communities, virtual laboratories, virtual institutes, etc., is hindered by the lack of a widely accessible body of knowledge on the related supporting concepts, technologies, and methodologies. Although considerable progress has been achieved in recent years, most of the underlying knowledge in this area is possessed only by a limited number of researchers and engineers. In fact, the study of collaborative networks is still absent from most of the traditional university programs.

There is therefore a lack of professionals, namely engineers ready to get engaged in projects on collaborative networks. The problem is augmented by the fact that proper approaches to the design, implementation, and operation of virtual organizations require contributions of a multi-disciplinary nature. Young engineers from the various engineering branches, although more or less aware of the potentialities offered by new technologies, have some difficulty in addressing multidisciplinarity. Moving from an enterprise-centric attitude, implicit in most engineering programs, to a collaborative network model requires a new mindset that calls for proper education programs.

The fact that collaborative networks are not recognized yet as a scientific discipline per se represents an obstacle for the introduction of VO courses in many 
university programs. Nevertheless some initiatives are already being reported [1], being important to share experiences and lessons learned with these early initiatives. In this context, this paper summarizes the experience of teaching a course on virtual enterprises / virtual organizations at the New University of Lisbon (UNL) in the academic years of 2002/2003 and 2003/2004.

\section{CONTEXT}

The Virtual Enterprises course was first included in 2002 as an elective subject in the Electrical and Computer Engineering program of the Faculty of Sciences and Technology of UNL. This one-semester course in offered to the 5th year engineering students (Fig. 1) and comprises a number of theoretical lectures and laboratory work sessions. The course spans over a period of 14 weeks, each week including $2 \mathrm{~h}$ of lectures and $3 \mathrm{~h}$ of lab work assisted by a teaching assistant.

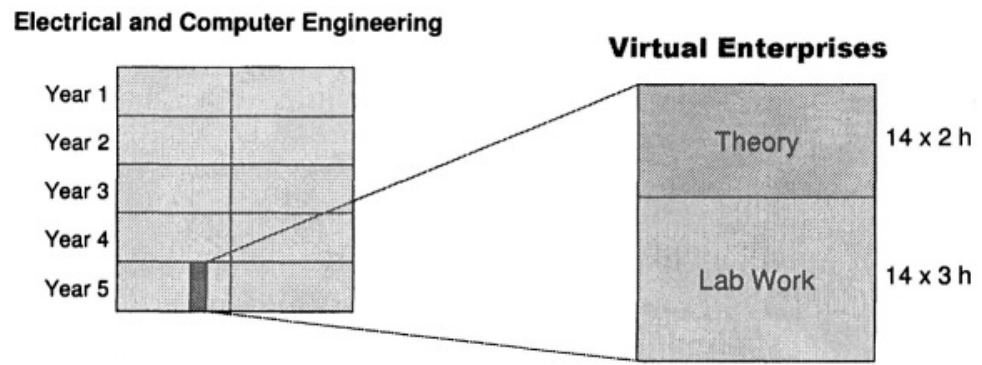

Figure 1 - Virtual Enterprises course in the Electrical and Computer Engineering program

Although an optional subject, that has to compete with many other courses offered by the UNL, this course attracted 21 students in 2002/2003 and 23 students in 2003/2004, which is a significant number considering that the total number of students in the $\mathbf{5}^{\text {th }}$ year of the Electrical and Computer Engineering program were about 45 .

The candidate students are supposed to have acquired a basic background in ICT during the previous semesters of the course (Fig. 2).

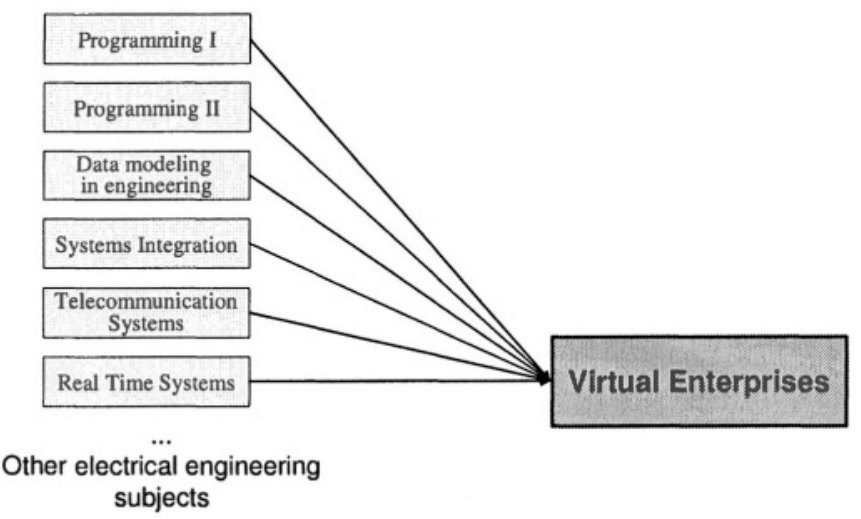

Figure 2 - Previous preparation on ICT of the candidates to the VE course 
Although the Electrical and Computer Engineering program of UNL includes more ICT subjects than other more traditional programs, it shall be noted that the focus is nevertheless on Electrical Engineering rather than Computer Science.

\section{COURSE CONTENTS}

The main theoretical subjects introduced in the 14 weeks are:

\section{UNIT 1: INTRODUCTION}

What is a VE? Why such subject in an Electrical and Computer Engineering course? Discussion of the program. Course evaluation methods. Practical (lab) work description.

\section{UNIT 2: BASIC CONCEPTS AND VE APPLICATIONS}

VE concept: various definitions - common elements. Related concepts VO, EE, .. --- collaborative networks. Why VE?

Application examples: Manufacturing, Large Scale Engineering, Civil Construction, Food industry / Agribusiness, Services, Government. Summary of motivations. Research projects - overview. Classes of VE. Roles in VE. Life cycle. Implementation difficulties. Clusters. New ways of working; new collaborative organizations: Virtual Labs, Remote supervision in manufacturing, Supervision in water distribution networks, Virtual Communities / Communities of Practice, VC in elderly care.

\section{UNIT 3: ORGANIZATIONAL FORMS OF VE}

Traditional manufacturing organizations. Supply chains. Emerging collaborative forms. Professional virtual communities. Other advanced collaborative forms. Structure and roles.

\section{UNIT 4: INFRASTRUCTURES FOR VE}

Why? For what purpose? Infrastructures and vertical services. Support for basic collaboration - Which functions. Support for advanced collaboration Which functions. Three approaches: Layer-based / transaction-oriented, MAS-based, Service federation. Example PRODNET. Examples MAS. Example of service federation. Interoperability.

\section{UNIT 5: SAFE COMMUNICATIONS IN VE}

Requirements. Basic mechanisms: Cryptography, Digital signature, Digital certificates, etc. Example architectures. Example from PRODNET. VPN.

\section{UNIT 6: DISTRIBUTED INFORMATION MANAGEMENT}

Requirements. Sharing and exchanging- which information: Business information, Product models, Distributed business processes, Contracts and cooperation agreements, Status information, quality information, etc. Privacy / visibility. Location transparency. Heterogeneity and autonomy pre-existing enterprises. Federated architectures: Federation in MAS, Federated Information Management Systems (FIMS). Combination MASFIMS. Shared spaces (ex. Concurrent engineering): CIM-FACE, Which information to share, Coordination and notification. 
UNIT 7: INFORMATION MANAGEMENT AND STANDARDS

EDI Concept and need. EDIFACT. XML. EDI+XML. ebXML.

\section{UNIT 8: PDM IN VE}

Product development as a collaborative activity. Information to share on products. PDM - functions. Standards in product information exchange. STEP. Examples: PRODNET and SAVE. APIs.

\section{UNIT 9: PORTALS AND BREEDING ENVIRONMENTS}

The concept of "portal". Catalogue of enterprises. Catalogue of services / resources. Examples of functionalities. Examples of architectures. Concept of breeding environment. Main requirements and examples.

\section{UNIT 10: COORDINATION IN VE}

Concept of coordination. Paradigms. Workflow concept. Workflow Management Coalition architecture. Examples: PRODNET, FETISH-ETF. Actors and roles in a VE.

\section{UNIT 11: DISTRIBUTED BP}

Concept of distributed business process. Multi-level coordination. DBP Planning. PIF, PSL.

\section{UNIT 12: PARTNERS SEARCH AND NEGOTIATION. E-CONTRACTS}

Agent-based approaches. Service federation approaches. Catalogue; profiles. WSDL. SOAP. UDDI. Contract negotiation and representation.

\section{UNIT 13: ELECTRONIC COMMERCE}

Basic Concept. Infrastructure: Electronic catalogue - Product - UPC, Service - WSDL, Which interface? Which base tools? E-Procurement RFQ, negotiation. "Show case", "Navigation" (browsing) and selection The problem of "soft" products (e.g. music). Delivery logistics. Payments. Examples. How to make your "shop" known.

\section{UNIT 14: VIRTUAL MARKETS}

Basic concept. Collective "Show case"- organizational paradigms. Communities. Infrastructure: Basic functionalities, Search and negotiation, Examples. Logistic integration. Payments. Integration B2B. Use of agents technology.

These lectures include a presentation of the main concepts, state of the art and supporting technologies, followed by a discussion of major trends and challenges. In all sessions an attempt to give students a holistic perspective of the area technology, socio-organizational concepts, and ethical issues - is made.

It is also important to note that the issues of enterprise modelling and integration, such as enterprise reference architectures, modelling tools, information integration, knowledge-based systems, supervision systems, and middleware technologies, were studied by the same students in a previous course (Systems Integration). The motivation was to clearly separate the traditional issues of single enterprise modelling from the collaborative networks. 


\section{LAB WORK}

The experimental work component of the course was designed to give students some hands on experience with a number of technologies that can be used in the development of VE / VO support infrastructures. Furthermore students are supposed to follow the main steps of a software engineering project and practice group work and inter-group collaboration. These objectives are achieved through the design and development of a case study.

The chosen case was the development of an ICT system to support the operation of a Professional Virtual Community of engineering consultants. In other words the objective of the lab work is the design and development of an ICT infrastructure for a Virtual Market of consultancy services (ConsultMarket_ICT). Engineering consultants that join this community shall be able to register (publish) their services / capacities. Furthermore, any member can become an intermediary and create some Value Added Services (VAS) based on the composition of a given set of services, in order to achieve a specific higher level goal. VAS can also be registered in the ConsultMarket_ICT, and accessed just like any other service. From the client,s point of view the ConsultMarket_ICT is regarded as a shopping place where he or she can find services needed for a given project.

The complexity of the intended infrastructure gives students the opportunity to use and integrate knowledge from different computer science areas, e.g. object oriented software construction, object oriented modelling, distributed systems, workflow systems.

Traditional software life cycle models and software quality principles pointed to the main phases of the work: Analysis, Design, Development, and Test. The first edition of the course (2002/2003) covered only the first 3 phases, while the second edition tried to go through the full process.

Analysis. The analysis phase started with the identification of the main requirements for the system architecture to be developed. For this purpose a forum was organized, where the students discussed the key ideas collected from some published papers related to the underlying areas (see references). Based on this discussion an Infrastructure Topology was identified, as well as the main requirements for the ConsultMarket_ICT, as shown in Fig. 3a and 3b.

\begin{tabular}{|c|c|c|}
\hline 8 & $\begin{array}{l}\text { - DBP Edition } \\
\text { - DBP Execution } \\
\text { - DBP Monitoring } \\
\text { - Web-Oriented } \\
\text { GUI } \\
\circ \text { Administration } \\
\circ \text { Maintenance } \\
\circ \text { BP } \\
\quad \text { Management } \\
\circ \ldots \\
\text { - ... }\end{array}$ & 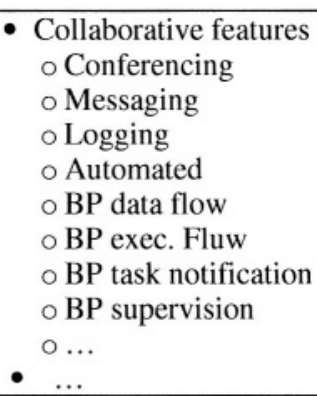 \\
\hline & \multicolumn{2}{|c|}{ DBP - Distributed Business Process } \\
\hline $\begin{array}{c}\text { Figure 3a) ConsultMarket_ICT } \\
\text { Topology }\end{array}$ & \multicolumn{2}{|c|}{$\begin{array}{c}\text { Figure 3b) ConsultMarket_ICT Main } \\
\text { Requirements }\end{array}$} \\
\hline
\end{tabular}


The next step was to detail the architecture for which the ICE methodology was used separating the architecture into three main categories of modules: Interface Modules, Control Modules and Entity Modules.

Students were divided in groups of three elements and each group proposed its own architecture. Based on a plenary discussion and analysis of the various suggestions, a common architecture was finally achieved, as shown in Fig. 4.

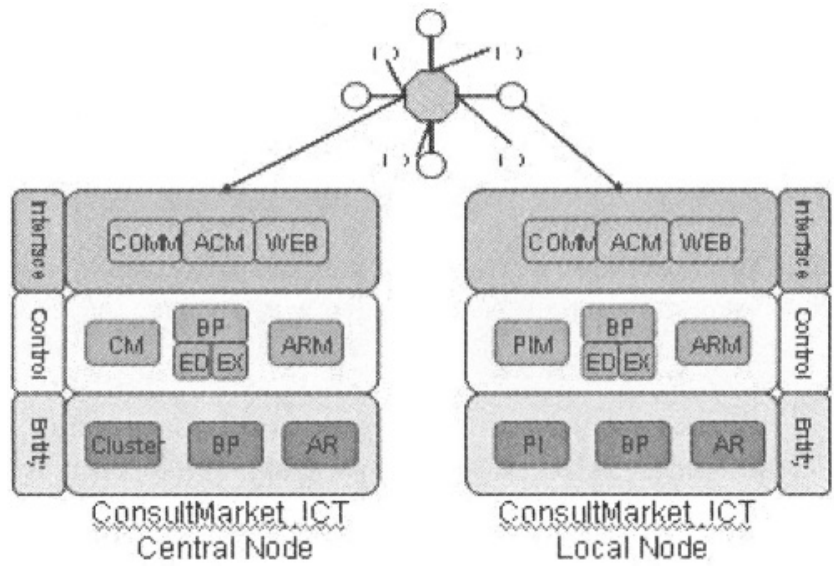

Figure 4 - ConsultMarket_ICT architecture

This architecture shows a star like structure, composed of a central node, the Community Main Node, and several local nodes, corresponding to the Members of the Community - the Consultants. Both nodes ended up with almost the same software modules. The reason is that the tasks are similar. The distinctive factor is the context where each module is working.

The next step was to formalize the description of the modules functionality into UML Use Cases. This was the base for the assignment of modules to the students, groups. Fig. 5 shows the main Use Cases for each module, using a UML like graphical language. Naturally, this was a first version that would evolve during the project. The Entity Modules, for instance, have the responsibility to store information. Thus their Use Cases are mainly concerned with setting and getting information. Nevertheless, whenever a given module needed some other Use Cases from any module a meeting was organized among the involved groups, opinions were exchanged and the creation of a new Use Case in the design phase took place. 


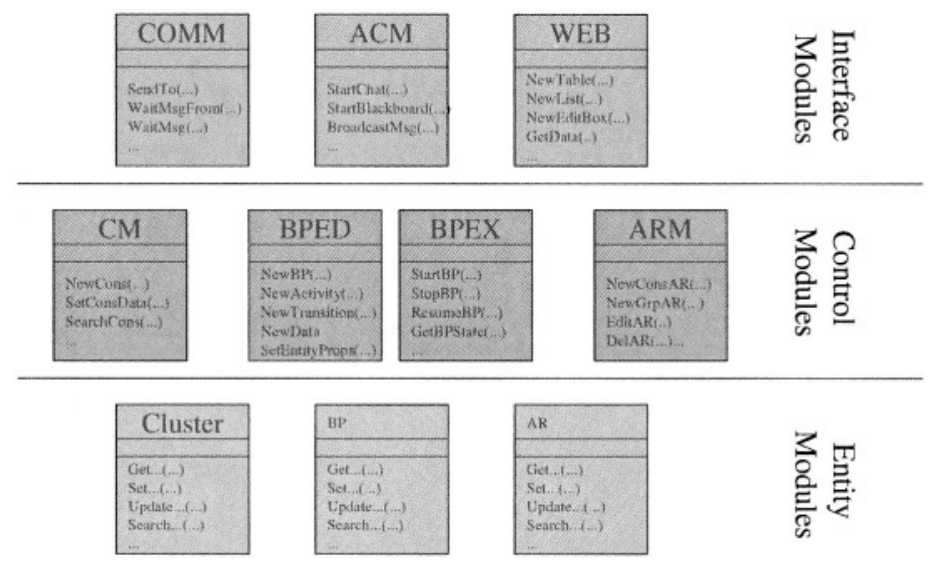

Figure 5 - Main Use Cases for the ConsultMarket_ICT Modules

Design. The design phase started with the division of work among distinct groups each group was assigned one or two modules of the architecture.

The second step in this phase was the definition of the technology to use in the subsequent phase. In the 2002/2003 edition, this was an a-priori decision, pointing out for a Java-based approach. In the 2003/2004 edition, the students performed an extra-task regarding the decision of what technology to use. In order to make this decision a number of technologies offered by different vendors were considered, namely:

- Sun Microsystems - A Java-based approach was a possibility, repeating the previous edition example. Sun Microsystems offered several copies of the Sun One Starter Kit,

- Microsoft - Another possibility was the usage of the .NET framework. A presentation of this technology was made by a Microsoft engineer.

- Oracle - Using the Oracle Databases was an a priori decision, due to their wide usage in the market. Furthermore, two technical presentations were made by Oracle engineers. The first one was an overview of the Oracle solutions and the second one was more focused on the Application Server and Workflow solutions.

- ARIS - Finally, the possible usage of the ARIS framework was presented by a group of students.

The .NET approach, based on the C\# language, integrated with an Oracle database, was the selected development environment. These sessions with industry engineers were quite informative and welcome by students.

After the technology decisions, each group had to produce two UML diagrams, complementing the Use Cases identified in the analysis phase:

- The first one was a Class Diagram, identifying what information their module would handle, as well as the operations it would support. Once more, the ICE methodology was used, making a distinction of Interface Classes, Control Classes, and Entity Classes. The later ones would have an image of the data stored in the database. Fig. 6 shows part of the Class Diagram created by the students group who developed the module responsible for the communication between modules. 


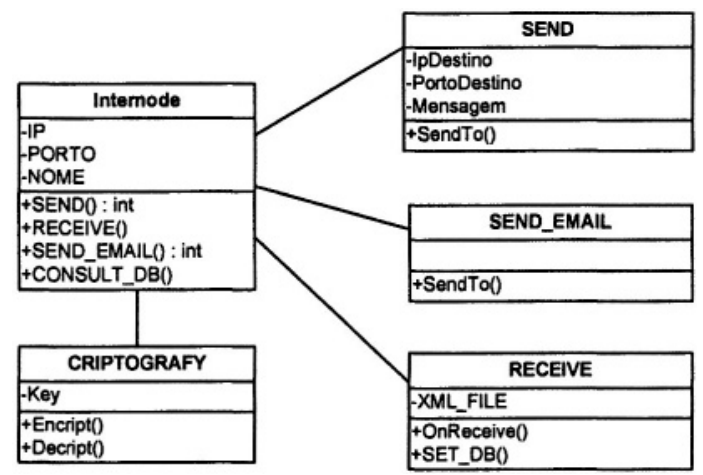

Figure 6- Part of the Internal Communications Module Class Diagram

- The second one was a set of UML Collaboration Diagrams, corresponding to each Use Case of the corresponding Module. These diagrams could be Sequence Diagrams, Activity Diagrams or State Transition Diagrams and their objective is the description of how each task should be done. The mainly used diagrams were Sequence Diagrams due to their fast creation and interpretation. Fig. 7 shows an example Sequence Diagram made by the students who implemented the Communications Module.

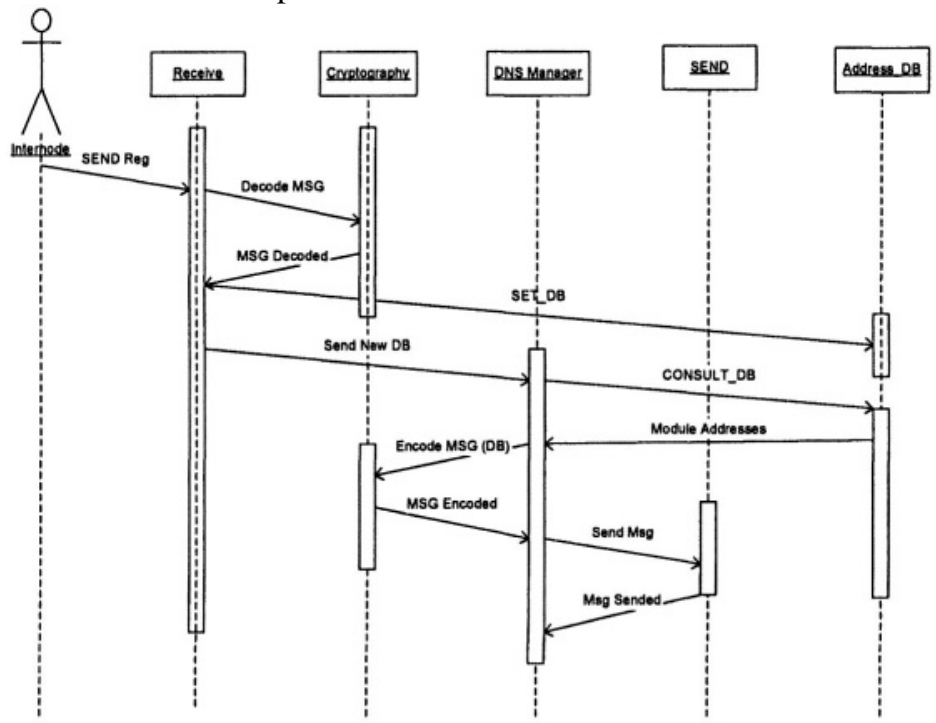

Figure 7 - Example Collaboration Diagram

In the 2002/2003 edition the design tool used for the production of these diagrams was the Rational Rose. In the 2003/2004 edition the decision of what design tool to use was also made by the students. Some students' groups prepared presentations regarding two possible options: Rational Rose and MEGA. Afterwards, a third possibility, the MetaMill system presented by one group, became the choice due to being the less heavy tool. 
Development and tests. The development and testing final lab works faced some difficulties due to the lack of experience of the students on distributed systems development, what required considerable extra work. Nevertheless, the final results were quite satisfactory due to the extra dedication of the students. The difficulties were concentrated mainly with message formats (Integration) and delays in the development of some modules. As a result some extra working evenings were required before the final demonstration...

The focus of the development was put on the key collaborative functionality and integration aspects. Therefore, only limited user interface was developed and the produced integrated system was, naturally, far from a robust, bug-free system.

\section{DIFFICULTIES AND LESSONS LEARNED}

Although these initial editions of the course have shown to be very useful for the students, both in terms of the theoretical background regarding VO/VE areas and the practical team work for a software development project, some difficulties were faced and some lessons learned:

- As the main focus of the students' previous education is electrical engineering, they are not very agile when it comes to software development and large systems integration, what requires a continuous assistance and extra time for the lab work.

- In particular, the extra working evenings required by the Testing Phase showed that the integration of technologies and inter-group interaction is a major difficulty, as it could be expected. Nevertheless this difficulty was highly valuable for the students' education.

- In order to facilitate the inter-group collaboration it became clear that a coordinator group among the students was needed. In the second edition of the course this was attempted, giving that task to the group that had the less complex module. Their main task was to supervise the design and development evolution, finding solutions whenever something wrong happens. Nevertheless this experience did not work very well and further attention shall be devoted to this issue in future editions.

- There is a "lack of tradition" of thinking holistically when the students reach this phase of their program. They are typically more motivated to think in narrow terms and easily loose track when different subjects and dimensions have to be considered at the same time.

\section{CONCLUSIONS}

The introduction of this course in the Electrical and Computer Engineering program of UNL, although with a short history, is being reasonably successful and contributing to the preparation of a new generation of engineers able to play a major role in the deployment of the VE/VO concept in the Portuguese industry.

In terms of Lab Work, this course was very useful to the students due to the fact that it is the first course where the students have to design and develop a real integrated and collaborative engineering work, taking a problem from the start, 
where things are not well specified in detail. Another new factor for the students was the creation of different pieces of a puzzle that would have to work integrated in the final demonstration. Naturally this factor implied several extra working hours, but the result was a very rich experience for the students. Finally, the students got a good picture of what is needed to support some collaborative networks in terms of infrastructures, since they had to develop one solution almost from scratch.

One of the main difficulties is the synchronization of the theoretical lectures and the progress in the lab work. As lab sessions are distributed along the semester, it often happens that some base concepts and models are needed in the lab before they are introduced in the theoretical lectures.

The wide experience acquired by the Robotics and Integrated Manufacturing Group of UNL through the participation in and leadership of many international research projects on VE/VO was a key enabling element to support this pilot initiative in the country. One aspect that needs to be monitored now is how many of these students actually get a job in this area and which feedback they can give to improve the course.

\section{REFERENCES}

1. COVE News $\mathrm{N}^{\circ}$ 6, Dec 2003. www.uninova.pt/ cove/COVENews6.pdf

Main bibliography used by students:

2. Camarinha-Matos, L. M.; Afsarmanesh, H. - Infrastructures for Virtual Enterprises - Networking industrial enterprises, Kluwer Academic Publishers, ISBN 0-7923-8639-6, IFIP Vol. 153, Sep. 1999.

3. Goranson, H. T. - The Agile Virtual Enterprise: Cases, Metrics, Tools. Quorum Books, 1999.

Additional references:

[Presented papers in the Analysis Forum]

1. Camannha-Matos, L. M.; Afsarmanesh, H. - The PRODNET architecture, in Proceedings of PROVE,99 - IFIP Int. Conf. on Infrastructures for Virtual Enterprises Kluwer Academic Publishers, ISBN 0-7923-8639-6, pp 109-126, Oct 99 Porto, Portugal.

2. Camarinha-Matos, L. M.; Afsarmanesh, H.; Rabelo, R. - Supporting agility in virtual enterprises, in Proceedings of PRO-VE 2000 - 2nd IFIP Working Conference on Infrastructures for Virtual Enterprises, Kluwer Academic Publishers, ISBN 0-7923-7205-0, pp89-104, Florianopolis, Brazil, 4-6 Dec 2000.

3. Camarinha-Matos, L. M.; Afsarmanesh, H. - Virtual Enterprise Modeling and Support Infrastructures: Applying Multi-Agent Systems Approaches, in Multi-Agent Systems and Applications, M. Luck, V. Marik, O. Stpankova, R. Trappl (eds.), Lecture Notes in Artificial Intelligence LNAI2086, pp335-364, Springer, ISBN 3-540-42312-5, July 2001.

4. Bremer, C.; Mundim.A.; Michilin, F.; Siqueira, J.; Ortega, L. - A Brasilian case of VE Coordination, in Proceedings of PRO-VE'99 - IFIP Int. Conf. on Infrastructures for Virtual Enterprises (L.M. Camarinha-Matos, H. Afsarmanesh-Eds.), Kluwer Academic Publishers, ISBN 07923-8639-6, Oct 99 Porto, Portugal.

5. Mejia, R.; Molina, A, - Virtual enterprise broker: processes, methods and tools, in Collaborative Business Ecosystems and Virtual Enterprises, (L.M.Camarinha-Matos, Editor), Kluwer Academic Publishers, ISBN 1-4020-7020-9, May 2002.

6. Katzy, B.; Sung, G. - Building Virtual professional communities, in Collaborative Business Ecosystems and Virtual Enterprises, (L.M.Camarinha-Matos, Editor), Kluwer Academic Publishers, ISBN 1-4020-7020-9, May 2002.

7. Osório, A.; Antunes, C.; Barata, M. - The PRODNET Communication Infrastructure, Proceedings of PRO-VE,99 - IFIP Int. Conf. on Infrastructures for Virtual Enterprises (L.M. Camarinha-Matos, H. Afsarmanesh-Eds.), Kluwer Academic Publishers, ISBN 0-7923-8639-6, Oct 99 Porto, Portugal. 